\title{
Psychiatric Morbidity Pattern in a Child and Adolescent Guidance clinic
}

\author{
Tulachan $\mathbf{P}^{1^{*}}$, Chapagain $\mathrm{M}^{2}$, Kunwar $\mathrm{AR}^{3}$, Sharma VD ${ }^{4}$ \\ Address: ${ }^{*}$ 1.Teaching Assistant, Department of Psychiatry and Mental Health, Institute of medicine 2.Lecturer, Department \\ of Psychiatry and Mental Health, Institute of medicine 3. Associate Professor, Department of Psychiatry, Kathmandu \\ Medical College \& Teaching Hospital 4.Professor, Head of Department, Department of Psychiatry and Mental Health, \\ Institute of medicine \\ Email *Corresponding author:prats38@gmail.com
}

\begin{abstract}
Introduction: There is a growing evidence of disabling mental illness among children and adolescents worldwide. The basic objective of the study was to study the socio-demographic characteristics and pattern of psychiatric disorders in children and adolescents attending the Child guidance Clinic of Tribhuvan University Teaching Hospital (TUTH) over a period of 11 months.
\end{abstract}

Material \& Method: A retrospective study of the clinical profile of children and adolescent patients attending the Child and Adolescent Guidance Clinic of TUTH was done. Diagnoses were made according to the criteria given in the Diagnostic and Statistical Manual of Mental Disorders, $4^{\text {th }}$ edition, Text Revision.

Results: A total of 188 new cases were registered from 1st May, 2009 to $30^{\text {th }}$ March, 2010. Significant (38.2\%) number of them were in between $10-12$ years with mean age of $9.79 \pm 3.33$ years and majority $(n=113,60.1 \%)$ were boys. Significant (25\%) number of referral was from other out patient departments of TUTH, especially pediatric outpatient department (OPD). The commonest condition was mental retardation (26.4\%), followed by somatoform disorders $(20.5 \%)$ and attention deficit hyperactive disorder together with disruptive behavior disorder (14.5\%).

Conclusion: The commonest psychiatric morbidity in patients attending a hospital based child and adolescent psychiatry OPD are mental retardation, somatoform disorders and attention deficit hyperactive disorder together with Disruptive Behavior disorder. This finding has to be taken with consideration that this is a retrospective study and study sample was limited to a hospital outpatient.

Key Words: Child Guidance Clinic, Psychiatry Morbidity, Mental Retardation

\section{INTRODUCTION}

All over the world, childhood and adolescent mental health has not received sufficient attention. Epidemiological studies have shown that there's growing evidence of disabling mental illness among children and adolescents worldwide. Prevalence of mental disorders among children has been reported to be $14-20 \%{ }^{1}$ According to the World Health Report (2000), $20 \%$ of children and adolescents suffer from a disabling mental illness worldwide ${ }^{2}$ and suicide is the third leading cause of death among adolescents. ${ }^{3}$ Recently, a literature search for epidemiological studies from 51 Asian countries has shown the general prevalence of childhood and adolescent mental health problems/disorders to be in the range of 10 $20 \%{ }^{4}$
Studies reveal lack of attention to the mental health of children and adolescents may lead to mental disorders with lifelong consequences, undermines compliance with health regimens, reduces the capacity of societies to be safe and productive and even put an economic impact to the country. ${ }^{5-7,8}$ Therefore, it is imperative to develop an accessible and effective mental health service. However, lack of data on precise figures and pattern of diseases have made this task difficult.

Studies from neighbor country India have revealed the prevalence rates of $12.5 \%$ in $0-16$ yrs community based sample from Bangalore, $9.4 \%$ in $8-12$ yrs olds from a community sample in Kerala and $6.3 \%$ in $4-11$ yrs old school children in Chandigarh. ${ }^{9-11}$ Regarding pattern of psychiatry morbidity, studies in India have shown much variation. However, mental retardation, neurosis, 
emotional and behavioral disorders and epilepsy formed the major groups of disorders. ${ }^{12-15}$ In Nepal, considering that under 18 populations constitute approximately $46.06 \%$ of the total projected population, we can imagine the magnitude of the problem in the country. ${ }^{16}$

Few surveys have been conducted in Nepal, the earliest study available is by Shrestha where he analyzed the data of a private clinic and found that children accounted for $8 \%$ (105) of his total patients. ${ }^{17}$ His study concluded that majority were suffering from mental retardation followed by neurosis and epilepsy.

Another study by Nepal et al found that majority of children attending the psychiatric OPD of TUTH were suffering from epilepsy. ${ }^{18}$ Regmi et al found children were $3.34 \%$ of the total outpatient population and more than half were suffering from mental retardation. ${ }^{19}$ Regmi et al found majority of children attending CGC (Child Guidance Clinic) were suffering from behavioral and emotional disorders $(31.75 \%) .{ }^{20}$ Similarly, another study by Pokharel et al found most of the patients were suffering from neurotic, stress related and somatoform disorders $(26.74 \%))^{21}$

In developing countries like Nepal, child and adolescent psychiatric problems are very often neglected. There is a lack of specialized child psychiatric units and awareness regarding mental illness at community as well as at the level of medical practitioners and other health care providers. The objective of this study was to determine pattern of psychiatric morbidity among children and adolescent patients attending a Child Guidance Clinic of a tertiary care hospital.

\section{MATERIAL AND METHOD}

It was a retrospective analysis of case records. The case records included the history taken from the parents as well as the children. The detail demographics and diagnosis were obtained. Diagnoses were made according to the criteria given in the DSM-IV TR. Data analysis was done in SPSS (Version 11.5, SPSS Inc., and Chicago, USA) Results were presented as frequencies and percentages where required.

\section{RESULTS}

A total of 188 new cases comprising of 113 boys and 75 girls attended the child guidance clinic during the study period. Maximum children were in the age group 10-12 years $(38.2 \%)$ and $7-9$ years $(24.4 \%)$, those under five years being comparatively less $(16.9 \%)$. The mean age of the patients was $9.79 \pm 3.33$ years. The minimum age of the patient attending clinic was 2 years and maximum was 18 years. (Table. 1)The significant number of cases 47 (25\%) were referred from Pediatric OPD of same hospital.

In the present study, 151 children and adolescents $(80.3 \%)$ were suffering from psychiatric disorders and $19(10.1 \%)$ were suffering from other disorders, while; no disorder Tulachan et al: Psychiatric Morbidity Pattern in Child and Adolescent Guidance clinic was detected in 18 (9.5\%). Among the patients with psychiatric disorders, most of the patients were suffering from mental retardation $(n=40,26.4 \%)$, followed by somatoform disorders $(n=31,20.5 \%)$ and ADHD along with Disruptive behavior disorder $(n=22,14.5 \%)$. Out of the patients suffering from disorders other than psychiatric disorders, majority $14(73.6 \%)$ were suffering from epilepsy. (Table. 2)

\section{Table I: Age Distribution of Children}

\begin{tabular}{|l|l|l|l|}
\hline Age Group(years) & $\begin{array}{c}\text { MaleNo. } \\
(\%)\end{array}$ & $\begin{array}{c}\text { FemaleNo. } \\
(\%)\end{array}$ & $\begin{array}{c}\text { Total No. } \\
(\%)\end{array}$ \\
\hline $1-3$ & $7(6.1)$ & $2(2.6)$ & $9(4.7)$ \\
\hline $4-6$ & $20(17.6)$ & $3(4)$ & $23(12.2)$ \\
\hline $7-9$ & $29(25.6)$ & $17(22.6)$ & $46(24.4)$ \\
\hline $10-12$ & $35(30.9)$ & $37(49.3)$ & $72(38.2)$ \\
\hline $13-15$ & $20(17.6)$ & $15(20)$ & $35(18.6)$ \\
\hline $16-18$ & $2(1.7)$ & $1(1.3)$ & $3(1.5)$ \\
\hline Total & 113 & 75 & 188 \\
\hline Mean Age & $9.79 \pm 3.33$ & & \\
\hline
\end{tabular}

Table II: Pattern of Psychiatric morbidity in Child Guidance Clinic

\begin{tabular}{|c|c|c|c|c|}
\hline \multicolumn{2}{|c|}{ Classification } & Disorder & $\begin{array}{l}\text { No. } \\
(\%)\end{array}$ & $\begin{array}{l}\% \text { of } \\
\text { Total }\end{array}$ \\
\hline \multirow{20}{*}{$\begin{array}{c}\text { DSM } \\
\text { IV- } \\
\text { TR }\end{array}$} & \multirow{6}{*}{$\begin{array}{l}\text { Disorder usually first } \\
\text { diagnose in infancy, } \\
\text { childhood,or } \\
\text { adolescence }\end{array}$} & MR & $40(26.4)$ & 21.2 \\
\hline & & PDD & $11(7)$ & 5.8 \\
\hline & & ADHD & $19(12.5)$ & 10.1 \\
\hline & & $\mathrm{CD} / \mathrm{ODD}$ & $3(1.9)$ & 1.5 \\
\hline & & Tic Disorder & $3(1.9)$ & 1.5 \\
\hline & & \begin{tabular}{|l|} 
Separation \\
Anxiety \\
Disorder
\end{tabular} & $1(0.6)$ & 0.5 \\
\hline & Delirium & Delirium & $1(0.6)$ & 0.5 \\
\hline & $\begin{array}{l}\text { Mental Disorders due to } \\
\text { GMC }\end{array}$ & $\begin{array}{c}\text { Mental Disorders } \\
\text { due to GMC }\end{array}$ & $1(0.6)$ & 0.5 \\
\hline & Schizophrenia & Schizophrenia & $1(0.6)$ & 0.5 \\
\hline & \multirow{2}{*}{ Mood Disorders } & MDD & $6(3.9)$ & 3.1 \\
\hline & & Mania & $1(0.6)$ & 0.5 \\
\hline & \multirow[t]{4}{*}{ Anxiety Disorders } & OCD & $1(0.6)$ & 0.5 \\
\hline & & PTSD & $2(1.3)$ & 1.06 \\
\hline & & ASD & $7(4.6)$ & 3.7 \\
\hline & & $\begin{array}{l}\text { Anxiety Dis. } \\
\text { Nos }\end{array}$ & $13(8.6)$ & 6.9 \\
\hline & Somatoform Disorders & $\begin{array}{l}\text { Somatoform } \\
\text { Disorders }\end{array}$ & $31(20.5)$ & 16.4 \\
\hline & Sleep Disorders & \begin{tabular}{c|} 
Sleep \\
Disorders \\
\end{tabular} & $3(1.9)$ & 1.5 \\
\hline & Adjustment Disorder & \begin{tabular}{|l|} 
Adjustment \\
Disorder \\
\end{tabular} & $5(3.3)$ & 2.6 \\
\hline & \multirow[t]{2}{*}{$\begin{array}{l}\text { Other conditions that may } \\
\text { be focus of clinical attention }\end{array}$} & $\begin{array}{c}\text { Medication } \\
\text { Induced } \\
\text { Movement } \\
\text { Disorder } \\
\end{array}$ & $1(0.6)$ & 0.5 \\
\hline & & Bereavement & $1(0.6)$ & 0.5 \\
\hline \multicolumn{3}{|c|}{ Total psychiatric disorders } & 151 & 80.3 \\
\hline \multirow[t]{4}{*}{ Other } & \multirow{4}{*}{ physical illness } & OtherEpilepsy & $14(73.6)$ & 7.4 \\
\hline & & \begin{tabular}{|l|l|}
$\mathrm{CP}$ \\
\end{tabular} & $1(5.2)$ & 0.5 \\
\hline & & Migraine & $3(15.7)$ & 1.5 \\
\hline & & $\begin{array}{l}\text { Spasmodic } \\
\text { Torticollis }\end{array}$ & $1(5.2)$ & 0.5 \\
\hline \multicolumn{3}{|c|}{ Total physical illness } & 19 & 10.1 \\
\hline None & $\begin{array}{l}\text { No psychiatric or } \\
\text { physical illness }\end{array}$ & $\begin{array}{c}\text { No psychiatric } \\
\text { or physical } \\
\text { illness }\end{array}$ & 18 & 9.5 \\
\hline
\end{tabular}




\section{DISCUSSION}

Globally research literature on the childhood psychiatric disorders is scarce and there are only few studies in Nepal. In the present, there were no cases up to two years of age and under 5 years made $16.9 \%$ of cases only (Table 1), this is similar to what has been reported in other studies from Nepal. ${ }^{20.21}$

Predominance of males in our and other reports ${ }^{20,21}$ could be due to gender based differential help seeking as more importance is given to boys in Nepal. Another reason for higher proportion of male registrations could be that boys have higher frequency of externalizing disorders which are more easily picked up.Significant number of the referrals had come from pediatric department which shows increasing awareness of pediatricians regarding child mental health.

The high prevalence $(26.4 \%)$ of mental retardation in the present sample may be due to the need for issuing of medical certificates for disability benefit or the high prevalence of behavioral problems associated with mental retardation. Similar high prevalence has also been reported by Shrestha ${ }^{17}$ and Regmi et al. ${ }^{19}$ Mental retardation forming the commonest diagnosis is a good sign, considering the age group, at which the parents were able to recognize or suspect the abnormality ( $25 \%$ were within 6years), and reached the psychiatrist. This reflects the increasing awareness about psychiatry. Such a healthy trend can go a long way in proper assessment, planning, training and future rehabilitation of the child depending on level of retardation. Also of note is lack of developmental pediatric services in Nepal for such children; who are often referred to psychiatrist for management.

Somatoform disorders made the second major group, was seen in $20.5 \%$ cases, an observation similar to that of Nepal et al and Pokharel et al. ${ }^{21,18}$ There were more females than males. In our country, child rearing is more authoritative and free verbal expression of emotions in children, especially by girls is not encouraged which could lead to expression through conversion to bodily symptoms. It appears that there is a higher prevalence of dissociative (conversion) disorders in South Asian countries as compared to the west. Since the disorder has bodily manifestations, it is brought to medical attention more often.

The third major group comprised of ADHD and disruptive behavior disorder together $(14.5 \%)$, high prevalence of behavioral and emotional disorder is in agreement with studies done by Regmi et al and Pokharel et al. ${ }^{20,21}$ The significant proportion of children with epilepsy in a psychiatric clinic probably reflects the lay thinking that it is a psychological disorder and therefore, the parents take the child to the psychiatrist rather than the pediatrician. This also reflects the practice pattern of psychiatrist in Nepal, where traditionally seizure disorders have been managed by a psychiatrist due to lack of Neurologist.

\section{CONCLUSION}

The data presented and reviewed above gives us some estimates of the extent and the nature of psychiatric problems seen among children in Nepal. It is evident th. there is considerable psychiatric morbidity which is likel to go up as the country is going through considerable changes (such as urbanization, impact of civil an. worldwide crises involving children impacted by war. exploited for labor and sex, orphaned by AIDS, and forced to migrate for economic and political reasons). Therefore. this would call for much more attention to be given for creating awareness in public and health professionals and to augment the services for these patients.However one has to bear in mind that present study being exclusively hospital based and the data obtained is retrospective, provides only a window view to actual depth of the psychiatric problems in children in Nepal. Further prospective studies and community based studies are needed in this area.

\section{REFERENCES}

1. Brandenburg NSA, Friedman RM, Silver SE. The epidemiology of childhood psychiatric disorders: Prevalence findings from recent studies. J Am Acad Child Adolesc Psychiatry 1990; 29:76-83.

2. WHO. The World Health Report 2000- Health Systems: Improving performance. Geneva: World Health Organization; 2000.

3. WHO. Mental health: New understanding, new hope. The World Health Report. Geneva: World Health Organization; 2001.

4. Srinath S, Kandasamy P, Golhar T. Epidemiology of child and adolescent mental health disorders in Asia. Current Opinion in Psychiatry 2010; 23(4):330-6.

5. Weissman MM, Wolk S, Goldstein RB, et al. Depressed adolescents grown up. JAMA 1999; 281(18):1707-13.

6. Leibson CL, Katusic SK, Barbaresi WmJ, et al. Use and costs of medical care for children and adolescents with and without attention-deficit/hyperactivity disorder. JAMA 2001; 285(1):60-66

7. Geller B, Zimerman B, Williams M, et al. Bi-polar disorder at prospective follow-up of adults who had prepubertal major depressive disorder. Am J Psychiatry 2001; 58:125-7.

8. Scott S, Knapp M, Henderson J, et al. Financial cost of social exclusion: follow-up study of anti-social children into adulthood. British Medical Journal 2001; 322:191-5. 
9. Srinath S, Girimaji SC, Gururaj G, Seshadri S, Subbakrishna DK, Bhola P, et al. Epidemiological study of child and adolescent psychiatric disorders in urban and rural areas of Bangalore, India. Indian J Med Res 2005; 122:67-79.

10. Hackett $R$, Hackett $L$, Bhakta $P$. The prevalence and associations of psychiatric disorders in children in Kerala, South India. J Child Psychol Psychiatry 1999; 40:801-7.

11. Malhotra S, Kohli A, Arun P. Prevalence of psychiatric disorders in school children in India. Indian J Med Res 2002; 116:21-8.

12. Chadda RK. Psychiatric Morbidity in Preschool Children - AClinic Based Study Indian J Pediatr 1995; 62:77-81.

13. Singhal PK, Bhatia MS, Balkrishna NK, Dhar DN, Mullick, Bohra N. Psychiatric morbidity. Indian J Pediatr 1988; 55:575-9.

14. Anita, Gaur DR, Vohra AK, Subash S, Khurana H. Prevalence of Psychiatric Morbidity among 6 to 14 years old children. Indian Journal of Community Medicine 2003 Jul-Sept; 28(3).

15. Chaudhury S, Prasad PL, Zacharias R, Madhusudan T, Saini R. Psychiatric Morbidity Pattern in a Child Guidance Clinic. MJAFI 2007; 63(2).

16. Statistical Year Book Of Nepal 2009,Central Bureau of Statistics

17. Shrestha DM. Neuropsychiatric problems in children attending a general psychiatric clinic in Nepal. Nepal Pediatric Society Journal 1986; 5:97-101.

18. Nepal MK, Sharma P, Gurung CK. The first child psychiatric clinic: an initial appraisal. NEPAS 1988; 7(1):71-5.

19. Regmi SK, Khalid A, Nepal MK, Pokhrel A. A study of Sociodemographic characteristics and diagnostic profile in psychiatric outpatients. Nepalese Journal of Psychiatry 1999; 1(1):26-33.

20. Regmi SK, Nepal MK, Khalid A, Sinha UK, Kiljunen R, Pokharel A et al. A study of children and adolescents attending the child guidance clinic of a general hospital. Nepalese Journal of Psychiatry 2000; 1(2):90-7.

21. Pokharel A, Ojha SP, Koirala NR, Regmi SK, Pradhan $\mathrm{SN}$, Sharma VD, et al. A profile of children and adolescents referred by paediatricians to the child guidance clinic of Tribhuban teaching hospital. Nepalese Journal of Psychiatry 2001; 2:116-22. 